\title{
Revisiting the evidence for genotoxicity of acrylamide (AA), key to risk assessment of dietary AA exposure
}

\author{
Gerhard Eisenbrand $^{1}$ (D)
}

Received: 14 April 2020 / Accepted: 20 May 2020 / Published online: 3 June 2020

(c) The Author(s) 2020

\begin{abstract}
The weight of evidence pro/contra classifying the process-related food contaminant (PRC) acrylamide (AA) as a genotoxic carcinogen is reviewed. Current dietary AA exposure estimates reflect margins of exposure (MOEs) $<500$. Several arguments support the view that AA may not act as a genotoxic carcinogen, especially not at consumer-relevant exposure levels: Biotransformation of AA into genotoxic glycidamide (GA) in primary rat hepatocytes is markedly slower than detoxifying coupling to glutathione (GS). Repeated feeding of rats with AA containing foods, bringing about uptake of $100 \mu \mathrm{g} / \mathrm{kg} / \mathrm{day}$ of AA, resulted in dose $\mathrm{x}$ time-related buildup of AA-hemoglobin $(\mathrm{Hb})$ adducts, whereas $\mathrm{GA}-\mathrm{Hb}$ adducts remained within the background. Since hepatic oxidative biotransformation of AA into GA was proven by simultaneous urinary mercapturic acid monitoring it can be concluded that at this nutritional intake level any GA formed in the liver from AA is quantitatively coupled to GS to be excreted as mercapturic acid in urine. In an oral single dose-response study in rats, AA induced DNA $N^{7}$-GA-Gua adducts dose-dependently in the high dose range (>100 $\left.\mu \mathrm{g} / \mathrm{kg} \mathrm{b} \mathrm{w}\right)$. At variance, in the dose range below $100 \mu \mathrm{g} /$ $\mathrm{kg}$ b.w. down to levels of average consumers exposure, DNA $N^{7}$-Gua lesions were found only sporadically, without dose dependence, and at levels close to the lower bound of similar human background DNA $N^{7}$-Gua lesions. No DNA damage was detected by the comet assay within this low dose range. GA is a very weak mutagen, known to predominantly induce DNA $N^{7}$-GA-Gua adducts, especially in the lower dose range. There is consensus that DNA $N^{7}$-GA-Gua adducts exhibit rather low mutagenic potency. The low mutagenic potential of GA has further been evidenced by comparison to preactivated forms of other process-related contaminants, such as $\mathrm{N}$-Nitroso compounds or polycyclic aromatic hydrocarbons, potent food borne mutagens/carcinogens. Toxicogenomic studies provide no evidence supporting a genotoxic mode of action (MOA), rather indicate effects on calcium signalling and cytoskeletal functions in rodent target organs. Rodent carcinogenicity studies show induction of strain- and species-specific neoplasms, with MOAs not considered likely predictive for human cancer risk. In summary, the overall evidence clearly argues for a nongenotoxic/nonmutagenic MOA underlying the neoplastic effects of AA in rodents. In consequence, a tolerable intake level (TDI) may be defined, guided by mechanistic elucidation of key adverse effects and supported by biomarker-based dosimetry in experimental systems and humans.
\end{abstract}

Keywords Acrylamide $\cdot$ Glycidamide $\cdot$ Mode of action $\cdot$ Non genotoxic $\cdot$ Process related contaminants $\cdot$ Dietary exposure

\section{Introduction}

Acrylamide (AA) is one of several so-called process-related contaminants (PRCs) occurring in heat-processed food worldwide. Further dietary PRCs of similar widespread occurrence encompasses glycidol and glycidol esters, chlorinated propanols (MCPD) and their esters, furans and

Gerhard Eisenbrand

eisenbra@rhrk.uni-kl.de

1 University of Kaiserslautern, Germany (Retired), Kühler Grund 48/1, 69126 Heidelberg, Germany substituted furans and, depending on the type of process and the temperatures applied to food, heterocyclic aromatic amines (HAA), $N$-Nitroso compounds (NOC) and polycyclic aromatic hydrocarbons (PAH). This list may not be exhaustive and further PRC may come into focus.

Of note, assembling these contaminants into one group is merely reflecting their mode of generation. They are formed from food constituents during the various heat treatment processes foods may be exposed to. These include cooking, microwaving, frying, baking, grilling, roasting, smoking, and/or other forms of industrial and household processing under heat. 
In all other aspects, especially with regard to structures, exposure levels, mechanisms of biological action, and potency there are substantial differences within PRCs. It appears appropriate to differentiate a group of contaminants of high genotoxic, mutagenic and/or carcinogenic potency, such as the HAA, PAH, and NOC from the other compounds of comparatively lesser biological potency.

Historically, certain high potency genotoxic compounds have been detected in food and human-environment many years before the more recently discovered PRCs. As a consequence, mitigation measures have been developed and installed much earlier. It is therefore fair to state that as a consequence of more than 50 years of sustained mitigation and consumer education, dietary exposure to high potency PRCs in most cases decreased down to levels bringing about margins of exposure (MOE) close to or exceeding 10 000. The MOE approach normally utilizes a reference dose from an animal study associated with a low but measurable reponse which is compared to dietary intake estimates in humans (EFSA 2005). A MOE of 10000 is equivalent to exposure levels not considered by the European Food Safety Authority (EFSA) to imply a relevant health risk to consumers. In contrast, mitigation measures and consumer information for some of the lower potency PRCs have been developed and implemented essentially only within the last two decades.

In 2002, AA contamination was discovered in a range of heat-processed foods. AA was found to arise during cooking, frying, roasting, baking, and to originate from natural precursors, known as innocuous food constituents. The main reaction occurs by heat-induced Maillard reaction of reducing carbohydrates with asparagine (Tareke et al. 2002). Food contamination data monitored during subsequent years reflect research on mitigation measures and their continuous implementation. Mitigation endeavors and communication to the consumer by health authorities and industry essentially followed directions agreed upon in so-called mitigation toolboxes, e.g. the Acrylamide Toolbox (Food Drink Europe 2019). This has been met with some success, especially with respect to the reduction of peak contaminations. Yet, average dietary consumer exposure in Europe has been estimated to correspond to MOE values within a range of about $<100$ to $<500$. The MOE was defined in the case of AA as the $\mathrm{BMDL}_{10}$ of $0.17 \mathrm{mg} / \mathrm{kg} /$ day divided by the consumer's of $0.4-3.4 \mu \mathrm{g} / \mathrm{kg}$ bw/day. The $\mathrm{BMDL}_{10}$ was taken as the point of departure (POD) from a mouse carcinogenicity study, corresponding to the modelled dose rate associated with the lower bound confidence interval of a $10 \%$ enhanced Harderian gland tumor response (EFSA 2011, 2015).

Intriguingly, such a MOE range is orders of magnitude lower than the target MOE of 10000 for genotoxic carcinogens considered of low public health relevance. Hence the continuing endeavor to reduce consumers' exposure further, along with the ALARA principle (as low as reasonably achievable), cast into legal regulation by the European Union concerning mitigation of AA contamination in food (EU 2017).

During recent years toxicological risk assessment has experienced literally quantum jumps in methodology and predictive power. The advent of extremely powerful, ultrasensitive, and dependable analytical techniques, in conjunction with modern methods of cell and tissue biology, stem cell technology, and advanced in silico evaluation methods together have driven this spectacular progress. It encompassed, amongst others, continuous refinements in development and application of quantitative structure-activity relationships (QSAR), quantitative in vitro-in vivo extrapolation (QVIVE), physiologically based pharmacokinetic (PBBK) modelling, as well as combined omics technologies. Moreover, novel findings were provided from biomarker monitoring under experimental settings or in well-controlled human intervention studies. Altogether this has contributed to bring about deepened insights with respect to the elucidation of adverse outcome pathways and MOAs of agents like AA, considered genotoxic at consumer-relevant exposure levels.

\section{Hazard identification and characterization of AA}

\section{Metabolism and supposed mechanism of action}

AA is well absorbed and rapidly distributed systemically. In addition to directly reacting with nucleophilic groups of plasma proteins and cellular constituents, it is extensively metabolized, primarily in the liver and predominantly by coupling to glutathione (GS), either spontaneously and/or mediated by glutathione-S-transferases. As a Michael reactant, AA avidly adds to nucleophilic centers, such as mercapto- or amino-groups of structural and soluble plasma proteins, including the $\mathrm{N}$-terminal valine of hemoglobin $(\mathrm{Hb})$. The generated $\mathrm{Hb}$ adducts can serve as biomarkers reflecting long term exposure since they build up during the about 3-4 month lifetime of animal/human erythrocytes. By contrast, GS adducts are metabolically trimmed into $\mathrm{N}$-acetyl cysteine thioethers, known as mercapturic acids (MA) which are almost completely excreted in the urine within about $48 \mathrm{~h}$ after exposure. They, therefore, are preferentially utilized as short term exposure biomarkers and do not accumulate.

A second major AA biotransformation pathway consists of cytochrome P450 2E1 (CYP2E1)-mediated epoxidation into 2,3-epoxypropanamide, known as glycidamide (GA). GA is considered to be genotoxic since it can damage the DNA by covalent binding to nucleophilic centers, primarily to the nitrogen in position 7 of the DNA base guanine ( $N^{7}$-Gua). Metabolic formation of GA is considered as activating biotransformation responsible for genotoxicity, 
Reaction with thiol or amino groups of proteins (e.g. hemoglobin: Hb-adducts)

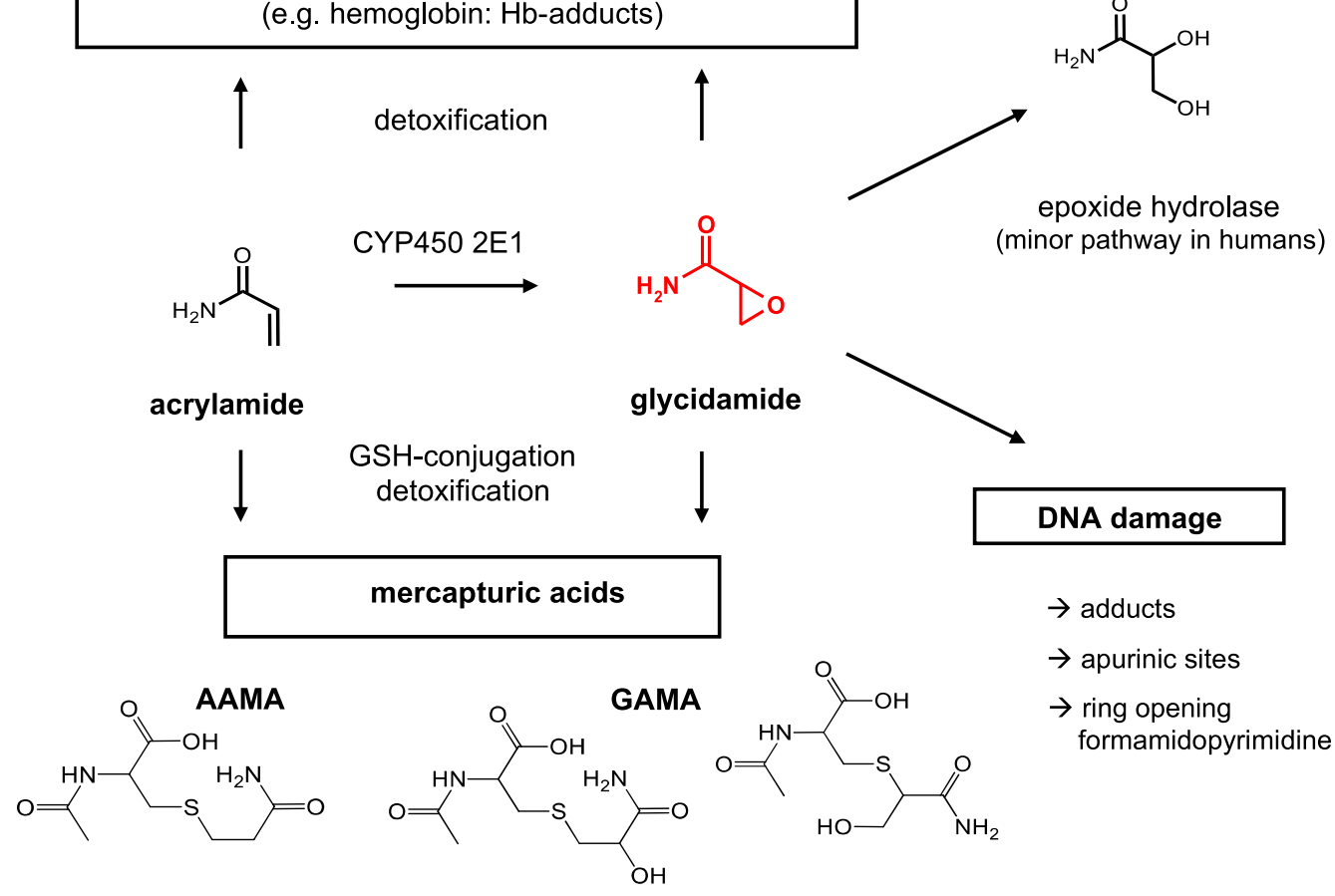<smiles></smiles>

N7-GA-guanine-adduct

Fig. 1 Major metabolic pathways of AA in the rat (reprinted from Hartwig et al. 2020)

mutagenicity, and carcinogenicity of the parent molecule, AA. The $N^{7}$-Gua adduct, $N^{7}$-(2 carbamoyl-2-hydroxy ethyl) guanine ( $N^{7}$-GA-Gua) is by far the most abundant DNA adduct derived from GA by covalent interaction. In contrast to GA adducts, covalent DNA adducts of AA itself have never been detected in vivo or in vitro in animal or human tissues. Figure 1 summarizes the relevant biotransformation pathways AA is undergoing in mammalian systems.

Of note, humans have been found to be less proficient than rodents in activating AA metabolically to the genotoxic metabolite GA, whereas detoxifying biotransformation, especially coupling of AA and GA to GS is more efficient in humans than rodents (Berger et al. 2011; Fennell and Friedman 2005; Fuhr et al. 2006). This species-related differential biotransformation, favoring detoxification in humans as compared to rodents, adds to the findings described below, showing that already in rat primary hepatocytes detoxification is faster than toxification at close to physiological conditions.

In an in vitro study, hepatic biotransformation was studied in primary rat hepatocytes incubated with $\mathrm{AA}$ in a wide range of concentrations $(0.2-2000 \mu \mathrm{M})$. Formation of GA from AA was measured in the medium, as well as the generation of the GS adduct, AA-GS. In addition, the formation of $N^{7}$-GA-Gua was also searched for. The formation of AA-GS was linear with AA concentration and incubation time and became detectable already at $0.2 \mu \mathrm{M}$ (4 h incubation). In contrast to AA-GS, GA was not detected before $16 \mathrm{~h}$ incubation at 10-fold higher AA concentration $(2 \mu \mathrm{M})$. In summary, the rate of AA-GS formation was found to be about 1.5-3 times faster than that of CYP-mediated GA formation. DNA $N^{7}$-GA-Gua adducts were found only at the highest AA concentration tested and after extended incubation times ( $2000 \mu \mathrm{M}, 24 \mathrm{~h}$ ), conditions far from being relevant to those expected to result from consumer's exposure. Altogether, at more physiological conditions, especially at low AA concentrations and incubation times better-reflecting conditions related to consumer exposure, evidence was compelling that in the rat liver detoxifying formation of GS adducts is up to about 3 times faster than GA formation (Watzek et al. 2013).

\section{Non-neoplastic effects}

Animal studies have been conducted in various species, including rodents, cats, dogs, and monkeys at a range of dosages and routes of repeated application. Key observations were peripheral neurotoxicity, adverse effects to the testes, atrophy of skeletal musculature, and further, rather unspecific toxicities observed at relatively high repeated dosage levels ( $\gg 1 \mathrm{mg} / \mathrm{kg}$ bw/day).

The EFSA CONTAM Panel identified four key outcomes of AA toxicity, i.e. neurotoxicity, effects on male reproduction, developmental toxicity, and carcinogenicity. Benchmark dose (BMD) analysis was performed using 
experimental data on neurotoxicity and carcinogenicity. For neurotoxicity, the lowest $\mathrm{BMDL}_{10}$ was $0.43 \mathrm{mg} / \mathrm{kg}$ bw/day, derived from the incidences of peripheral (sciatic) axonal nerve degeneration in male F344 rats exposed in drinking water for 2 years. Since this was lower than the no observed adverse effect levels (NOAELs) for adverse effects on male reproductive parameters and for developmental toxicity, the BMDL $_{10}$ for neurotoxicity was selected as a conservative reference point and point of departure (POD) for risk assessment of non-neoplastic effects (EFSA 2015).

\section{Neoplastic effects}

In long term studies, AA has exerted neoplastic effects in multiple tissues of rodents, in a dose range $>0.5 \mathrm{mg} / \mathrm{kg} \mathrm{bw} /$ day. These essentially included the enhanced formation of mammary gland adenomas and fibroadenomas, thyroid follicular cell adenomas/carcinomas, and mesotheliomas of testes (tunica vaginalis) in Fisher (F344) rats. In mice, neoplastic effects encompassed Harderian gland tumors, together with tumors of mammary gland, lung, ovary, skin, and stomach/forestomach papillomas/carcinomas (summarized in EFSA 2015).

The EFSA CONTAM panel has selected the lowest $\mathrm{BMDL}_{10}$ of $0.17 \mathrm{mg} / \mathrm{kg}$ bw/day, derived from data on the incidence of Harderian gland tumors in male $\mathrm{B} 6 \mathrm{C} 3 \mathrm{~F} 1$ mice continuously exposed to AA for 2 years. Although a Harderian gland is absent in humans, the rationale for this selection was

1. the consideration that this tissue was most sensitive in rodent bioassays to detect effects of genotoxic carcinogens and

2. Taking into account that target tissues for tumor formation by a given genotoxic carcinogen may differ between rodents and humans

The EFSA CONTAM Panel considered the MOE approach appropriate for risk characterization of neoplastic effects of dietary exposure to AA and derived MOE values ranging from about $<100$ to $<500$.

Of note and at variance with the aforementioned rodent carcinogenicity studies in mice and F344 rats primarily evaluated by EFSA, a two year carcinogenicity study carried out in a different rat strain (Wistar Han rats) brought about markedly divergent results (Maronpot et al. 2015). The design of this high quality and guideline compliant study encompassed transplacental exposure of pregnant animals from gestation day 6 until delivery, followed by continuous longterm treatment of the offspring. AA was applied in drinking water at a dosage range of $0.5-3 \mathrm{mg} / \mathrm{kg}$ bw/day. Male and female F1 offspring animals remained with the dams until day 21 of lactation and were randomized after weaning to the respective treatment subsets within each group. Offspring animals were continuously AA exposed at the same dosage until postnatal day 722 .

A dose-related increase in thyroid follicular cell neoplasms in males and females was observed. Also, mammary fibroadenomas were found enhanced in the two highest dosage groups. These were observed in the majority of cases in animals surviving to the 24 month terminal dissection (Maronpot et al. 2015). However, no testes tunica vaginalis mesothelioma (TVM) and only one Leydig cell tumor (LCT) were observed, indicating a clear strain difference between F344 and Wistar Han rats (Maronpot et al. 2015).

The development of TVM is considered to reflect a specific susceptibility of the F344 rat to Leydig cell tumors with secondary induction of TVM. Given their high spontaneous background incidence and species-specific biology TVM responses in F344 rat carcinogenicity studies, -along with LCT and mononuclear cell leukemia have been rated inappropriate tumor types for human health risk assessment, lacking relevance in predicting human carcinogenicity (Maronpot et al. 2009, 2015, 2016; Shipp et al. 2006). Other possible treatment-related neoplasms identified in previous F344 rat carcinogenicity studies did not occur in Wistar Han rats, including those of the clitoral gland, cardiac schwannomas, islet cell carcinomas, or oral cavity tumors.

Rat mammary gland fibroadenomas are typically not considered precursors of malignant mammary adenocarcinomas. In the study of Maronpot et al. (2015), the overall incidence of mammary gland fibroadenomas in females was not statistically significant and within the published control range for Wistar rats (Maronpot et al. 2015). For mammary fibroadenomas in rats the luteotrophic effect of age-associated prolactinaemia is supposed to be causative. This mode of action is considered not likely relevant to women where prolactin is not luteotrophic (Ben-Jonathan et al. 2008; Maronpot et al. 2009, 2015; Neumann 1991). Likewise, in a review on spontaneous neoplasms in control Wistar rats covering 10 years of observation, amongst other neoplasms a predilection to pituitary neoplasms and mammary fibroadenomas in females was noted (Poteracki and Walsh 1989).

Thyroid follicular cell neoplasms occurred late in this study (Maronpot et al. 2015). Follicular cell neoplastic responses had also been documented in previously conducted AA carcinogenicity studies in Fisher 344 rats (Beland et al. 2013; Friedman et al. 1995; Johnson et al. 1986). Thyroid follicular changes are known to be associated with rat-specific thyroid hormone homeostasis which differs markedly from thyroid follicular cell hormonal physiology in man (Alison et al. 1994; Capen 1997). At variance to humans, rats are uniquely susceptible to developing thyroid follicular cell neoplasms. This is known to reflect marked differences in plasma thyroid hormone turnover, preferentially resulting from a lack of thyroid-binding globulin in 
rodents. As a consequence, rodent thyroid is less proficient than the human thyroid to maintain thyroid hormone homeostasis. Moreover, the halflife of thyroid hormones T4 and $\mathrm{T} 3$ is very much shorter (about tenfold) in rodents than in humans and thyroid-stimulating hormone (TSH) levels are much higher in rodents. Thus, rodent thyroid is on a markedly higher activity level than its human counterpart which is supposed to make rats considerably more susceptible to neoplastic effects than humans (Alison et al. 1994; Dourson et al. 2008; Maronpot et al. 2015).

A role for hormonal dysregulation affecting the pituitary-thyroid axis and the rat specific thyroid hormonal milieu is generally accepted as an explanation for follicular cell neoplasia in rat carcinogenicity studies and is considered a rat-specific response (Alison et al. 1994; Bartsch et al. 2018; Capen 1997; Capen and Martin 1989; Khan et al. 1999; Maronpot et al. 2009, 2015; Neumann 1991). As genotoxic damage to the thyroid at the dosages applied is likely improbable, (as discussed below) such rodent thyroid tumors are conceived to result from continuous interference with the pituitary-thyroid hormonal homeostasis of rats and considered not likely relevant to humans.

In summary, in the described study in Wistar Han rats the observed tumor responses essentially were limited to the thyroid and mammary glands. Both of these target tissue-specific responses have rat-specific modes of action, not likely predictive for human cancer risk (Maronpot et al. 2015).

\section{Evidence from epidemiology}

A great number of epidemiological studies have been carried out throughout the years to investigate potential associations of exposure to AA with enhanced human cancer risk. According to EFSA (European Food Safety) (2015) the totality of epidemiological evidence from this wide range of human studies has not provided consistent indication for an association between AA exposure and increased cancer risk.

Few studies have utilized exposure biomarkers to approach more dependable dosimetry of AA. However, in most studies probable coexposure to other PRC has largely been disregarded. An unexpected recent discovery may have a greater bearing on the outcome of such epidemiological studies. Detailed monitoring of exposure biomarkers in carefully controlled human intervention studies has provided compelling evidence that certain PRC are continuously biosynthesized in the human body. For AA, this endogenous background exposure has been estimated to be relatively close to the average dietary exposure. Moreover, human endogenous exposure to the close AA analogue, acrolein (AC), has recently been reported to be even more than tenfold higher than that to endogenous AA (Goempel et al. 2017; Goerke et al. 2019; Ruenz et al. 2016, 2019). It may be presumed that such endogenous exposure may be variable, depending on as yet largely unknown factors of influence. The potential relevance of these findings, especially concerning the power to discover potential associations between AA exposure and human health risk, has yet to be addressed.

Continuous endogenous background exposure likely is not confined just to AA and AC but may comprise further electrophiles, arising from intermediary energy metabolism and/or from the human gut microbiome, including, for instance, several Michael reactive alkenals (Kiwamoto et al. 2015). Future epidemiological studies should take note of the consequences regarding the dosimetry of total human exposure. Thus, for a more appropriate estimate of potential human health consequences, well designed epidemiological and/or nutritional intervention studies will require elaborate and comprehensive dosimetry of the whole spectrum of PRCs in food and, in parallel, of their endogenously generated congeners, preferentially based on monitoring appropriate exposure biomarkers.

Finally, the association between occupational exposure to AA and cancer risk has been studied extensively, with longterm follow-up in 3 occupational cohorts of AA exposed workers (Collins et al. 1989; Marsh et al. 1999, 2007; Sobel et al. 1986; Swaen et al. 2007). These studies have shown no increased mortality from cancer overall or from specific cancer types, nor did they provide support for a positive dose-response among workers with respect to cumulative exposure and its duration or other exposure metrics (Pelucchi et al. 2011).

Overall, workers exposed at various working places to enhanced levels of AA have shown increased risk of mostly peripheral neurotoxicity, but no indication for an enhanced occupational cancer risk (summarized in EFSA 2015).

\section{Genotoxicity and mutagenicity}

The potential of an agent to damage DNA either directly by covalent binding or indirectly by otherwise altering its function and integrity commonly is referred to as genotoxic potential. The classical default position for regulatory authorities in cases of compelling evidence for genotoxicity was that there is no acceptable level of exposure (Gooderham et al. 2020). A more refined evaluation of the associated health risk however not only evaluates data on the genotoxic hazard, but also potential exposure, the dose-response relationship, and the key mode(s) of action, with emphasis on realistic consumers exposure scenarios.

\section{In-vitro data}

It is generally accepted that AA by itself is not a genotoxic and/or mutagenic agent at biologically relevant concentrations. To become active, it is supposed to require oxidative 
biotransformation into GA, primarily mediated by Cyp 450 2E1 (see Fig. 1) GA is assumed to act as the key genotoxic metabolite (Calleman et al. 1990; Segerbäck et al. 1995; Sumner et al.1999; Settels et al. 2008). GA has been shown to exert genotoxic and mutagenic effects in bacterial and mammalian test systems, whereas AA was found devoid of such activities at biologically relevant concentrations (Baum et al. 2005a, b; 2008; Hashimoto and Tanii 1985; Jiang et al. 2007; Koyama et al. 2006; Lamy et al. 2008; Mei et al. 2008; Puppel et al. 2005; Thielen et al. 2006).

GA, the activated genotoxic metabolite of AA, was tested in comparison with preactivated forms/model compounds of potent genotoxic and carcinogenic PRCs, using the comet assay in human blood/peripheral human lymphocytes as well as measuring induction of mutations and chromosomal damage.

In a first experiment, the potential of $\mathrm{AA}$ and GA to induce forward gene mutations in V79 Chinese hamster fibroblasts was compared using the hypoxanthine phosphoribosyl-transferase ( $h P R T)$ gene mutation assay in V79 cells. Cells were treated with AA $(100-10000 \mu \mathrm{M})$ or GA $(400-2000 \mu \mathrm{M})$ for $24 \mathrm{~h}$. AA did not induce mutations up to extremely, unrealistically high concentrations $(6-10 \mathrm{mM})$. With GA, significantly elevated mutation frequencies became detectable only from $800 \mu \mathrm{M}$ upwards. By contrast, the positive control N-methyl-N-nitro-N-nitroso-guanidine (MNNG), a potent and directly acting NOC, exerted within just 15 min of incubation marked mutagenic activity already at a concentration of $0.5 \mu \mathrm{M}$, orders of magnitude lower GA (Baum et al. 2005a).

In further experiments, a modified form of the comet assay was used, encompassing incubation of compounds in human whole blood (Baum et al. 2005a, b; Thielen et al. 2006). Whole blood may be considered as an ex vivo model system, containing a spectrum of proteins and other biomolecules with nucleophilic groups that may contribute to at least partially scavenging AA and GA by covalent binding after absorption from the gut. After $1 \mathrm{~h}$ incubation of human blood with $2,3,{ }^{14} \mathrm{C}$-AA $(30 \mu \mathrm{M})$, about $30 \%$ of the radiolabel was found in erythrocytes, $50 \%$ in protein-free plasma, and about $12-15 \%$ in plasma proteins (Bertow 2009). Thus, direct binding to noncritical blood constituents contributes to consuming a substantial portion of the bioavailable AA and its metabolite GA.

In this system the genotoxic/mutagenic activity of GA was compared with that of other activated/direct acting forms of known carcinogens: in addition to MNNG the benzo[a] pyrene metabolite $( \pm)$-anti-benzo[a]pyrene-7,8-dihydrodiol9,10-epoxide (BPDE) and activated forms of N-Nitroso compounds-, including alfa-acetoxy-N-nitroso-diethanolamine (A-NDELA) and (3-N-nitroso-oxazolidine-2-one, NOZ-2. Induction of micronuclei (MN) was measured by incubating phytohemagglutinin treated blood for $23 \mathrm{~h}$ with
AA (500-5 $000 \mu \mathrm{M})$ or GA $(50-1000 \mu \mathrm{M})$ or with appropriate concentrations of the described activated/directly acting forms of carcinogens. In short, these studies confirmed the presumption of GA being a genotoxic and mutagenic agent of a rather low potency. About $300 \mu \mathrm{M}$ of GA $(4 \mathrm{~h})$ were required to induce detectable DNA damage. By contrast, preactivated NOCs (3-N-nitroso-oxazolidine-2-one, NOZ-2 and A-NDELA) as well as a preactivated PAH, (( \pm$)$-antibenzo[a]pyrene-7,8-dihydrodiol-9,10-epoxide (BPDE) exerted very much stronger genotoxic activity than GA, inducing significant DNA damage after short incubation times (15 min) at concentrations of $3 \mu \mathrm{M}$, orders of magnitude lower than GA. Likewise, in the $h P R T$ mutagenicity test in V79 cells, GA-induced mutations only at concentrations of $800 \mu \mathrm{M}$ and above, whereas preactivated NOCs and PAH significantly induced $h P R T$ mutations already at more than 200 fold lower concentrations (Baum et al. 2005a, b; 2008; Thielen et al. 2006).

In a modification of the comet assay, lymphocyte DNA was additionally processed with the DNA repair enzyme formamido-pyrimidine-DNA-glycosylase (FPG) (Thielen et al. 2006). This can lead to an enhancement of strand breaks at positions where FPG recognizes apurinic and apyrimidinic sites, ring-opened pyrimidines (formamido-pyrimidines), and oxidized purines, representing DNA lesions conceived to result from oxidative DNA damage. They may, however, also arise as a consequence of DNA $N^{7}$ Gua alkylation. Whereas in the comet assay without additional FPG treatment GA induced significant DNA damage in lymphocytes only at $300 \mu \mathrm{M}$ and above, additional FPG processing led to the detection of DNA strand breaks already after $4 \mathrm{~h}$ incubation with $10 \mu \mathrm{M}$ GA. This may reflect oxidative damage and/or transient formation of DNA $N^{7}$-GA-Gua adducts which may subsequently generate apurinic sites (AP sites) via spontaneous or enzymatic depurination. AP sites are rapidly converted into strand breaks under the strongly alkaline comet assay standard conditions. Although therefore this individual experiment indicated some DNA interaction of GA at a lower concentration, GA induced DNA lesions are conceived to be rapidly repaired before eventually causing mutations. This presumption is compellingly supported by the above-reported findings. Direct DNA damage in lymphocytes became detectable by the comet assay only after incubation of blood with GA concentrations at or above $300 \mu \mathrm{M}$, in accordance with the $h P R T$ mutagenicity test in V79 cells, becoming positive only at elevated concentrations of $800 \mu \mathrm{M}$ and above. It may thus be inferred that at realistically low blood concentrations associated with dietary AA exposure, induction of DNA damage and mutations is not expected to take place. This presumption is further supported by taking into account that in vivo during the first pass through the liver, detoxifying GS coupling kinetically outperforms 
CYP mediated oxidative GA formation, as demonstrated in primary rat hepatocytes (Watzek et al. 2013).

At this point, it may be allowed to comment on certain quality criteria required to evaluate the merits of in vitro or in vivo studies and model experiments aimed to contribute to human risk assessment. As a major element of quality, exposure conditions chosen for such experiments need to be justified with respect to animal and human exposure, and toxicokinetics. In-vitro studies utilizing unrealistically high concentrations (i.e. any concentration markedly exceeding in vivo blood/tissue levels associated with worst-case environmental exposure) to become meaningful require compelling proof that relevant MOAs and toxicokinetics are not altered. For example, studying mutational signatures in human embryonal cells by $24 \mathrm{~h}$ treatment at $\mathrm{mM}$ concentrations of AA/GA for $24 \mathrm{~h}$ appears far away from physiological conditions. An interpretation of the results obtained under such extreme conditions as revealing "widespread contribution of acrylamide to carcinogenesis in humans "therefore is not convincing (Zhivagui 2019)".

\section{Taken together with the totality of the above described in vitro evidence compellingly reveals}

1. AA not to be genotoxic/mutagenic and

2. GA to exert at best very weak genotoxicity and mutagenicity (especially under biologically relevant conditions), compared to preactivated forms of established food borne mutagens and carcinogens.

The conclusion that GA is to be considered as a very low potency genotoxic and mutagenic agent can also be reconciled with its preferential DNA $N^{7}$-Gua alkylation. The propensity of DNA lesions to lead to mutations is dependent on several parameters, such as the type and topology of the lesion, the rate and correctness of DNA repair processes, induction of apoptosis, and proliferative response. As an overall consequence, the mutagenic potential of different DNA lesions ranges over several orders of magnitude (Nestmann et al. 1996). DNA $N^{7}$-Gua alkyl adducts are known to be frequently formed but may have minimal biological relevance since they are chemically unstable and do not participate in Watson-Crick base pairing. Thus little to no evidence has been ascribed to $N^{7}$-Gua alkyl adducts, as a noteworthy cause of mutations in cells and tissues (Boysen et al. 2009).

\section{In-vivo studies}

The following discussion concentrates on studies at realistic dietary AA exposure levels, i.e. those that may be expected from the intake of heat-processed foods. Data from such experimental studies in animals have been complemented by carefully controlled human intervention studies investigating the effects of dietary AA on human biomarker kinetics (Goempel et al. 2017; Goerke et al. 2019; Ruenz et al. 2016).

Early on after the discovery of AA as a PRC in food, the question of its bioavailability from the food matrix during digestion became relevant. Thus, in a systematic study in Sprague-Dawley (SD) rats, the bioavailability of AA from different food matrices was tested in comparison to AA from ingested drinking water.

AA was given to rats by feeding foods containing known amounts of AA (generated by heat processing) for up to 9 days, resulting in a dietary exposure of 50 or $100 \mu \mathrm{g} \mathrm{AA} /$ $\mathrm{kg}$ bw/day (Berger et al. 2011). Positive controls received the same dosages of AA in drinking water, negative controls just water. Short term and long-term exposure biomarkers were monitored, including urinary MAs and $\mathrm{Hb}$ adducts of $\mathrm{AA}$ and $\mathrm{GA}$ to the $\mathrm{N}$-terminal valine of $\mathrm{Hb}$. Plasma levels of AA and GA were monitored as well and induction of DNA damage in white blood cells and in liver cells (hepatocytes) was investigated using the in vivo comet assay.

Significant differences in overall bioavailability in terms of the area under the curve (AUC) values of AA ingested from water and different food matrices were not observed. Plasma kinetics of AA essentially showed peak values 30 min after intake, yet with about fourfold higher peak levels in animals after AA intake in water as compared to foods. The delayed plasma kinetics observed after food intake, reflecting delayed liberation from the various food matrices during digestion, lead however to about the same terminal AUC levels as from water, resulting in similar overall bioavailability (Berger et al. 2011).

Formation of $\mathrm{Hb}$ adducts of AA depicted linear timeand exposure-related dose-response, showing treatment associated cumulative buildup of AA Hb adducts in blood erythrocytes. In contrast, $\mathrm{Hb}$ adducts of GA were not found significantly enhanced above untreated control. This was remarkable since the urinary short time exposure biomarker of metabolically formed GA, the mercapturic acid $N$-acetylS-(2-carbamoyl-2-hydroxyethyl)cysteine (GAMA) indicated significant GA generation in the liver.

This result suggested that at the AA dose levels ingested, any GA formed metabolically in the liver was effectively scavenged by glutathione coupling (Berger et al. 2011).

Of note, the genotoxic AA metabolite GA was only detected at one single sampling point $(4 \mathrm{~h})$ in plasma in minute concentration, close to the detection limit $(0.06 \mu \mathrm{M})$. This supports the interpretation that at dietary exposure level, GA, as soon as it is metabolically formed in the liver, is directly and practically quantitatively scavenged by GSH coupling. The GSH adduct is metabolically further processed into the corresponding mercapturic acid and excreted in the urine, thus allowing biomarker-based dosimetry of the GA formed from AA at first pass in the liver. As a further confirmation of absent genotoxicity, the comet assay values 
did not show any enhanced DNA damage in liver or blood cells under any dietary exposure condition, compared to untreated control (Berger et al. 2011).

In a subsequent dose-response study AA was given orally in single doses of $0.1-10000 \mu \mathrm{g} / \mathrm{kg}$ bw to female SD rats (Watzek et al. 2012a). The lowest dose $(0.1 \mu \mathrm{g} / \mathrm{kg} \mathrm{bw})$ was below average dietary consumers' exposure $(0.4-0.6 \mu \mathrm{g} / \mathrm{kg}$ bw) the next higher dose $(1 \mu \mathrm{g} / \mathrm{kg})$ close to this level. Further dose escalation was achieved by factors of 10 , up to the highest dose. Formation of urinary MAs and of $N^{7}$-GA-Gua DNA adducts in liver, kidney, and lung was measured $16 \mathrm{~h}$ after application, a time point where a previous pilot experiment had shown maximal.

\section{$N^{7}$-GA-Gua DNA concentration to occur}

Although mercapturic acid monitoring clearly reflected escalating dose-related responses, DNA- $N^{7}$-GA-Gua adduct formation behaved quite differently. Enhanced formation in comparison to untreated control was not detectable in any organ tested at $0.1 \mu \mathrm{g} \mathrm{AA} / \mathrm{kg}$ bw. At a dose of $1 \mu \mathrm{g} / \mathrm{kg}$ bw, adducts were found in the kidney (about 1 adduct $/ 10^{8}$ nucleotides) and lung (below 1 adduct $/ 10^{8}$ nucleotides), but not in liver. At 10 and $100 \mu \mathrm{g} / \mathrm{kg}$ bw, respectively, adducts were found in all three organs, however at levels close to those found at $1 \mu \mathrm{g} \mathrm{AA} / \mathrm{kg}$, in a range of about $1-2$ adducts $/ 10^{8}$ nucleotides. Thus, in the dose range from 0.1 to $100 \mu \mathrm{g} / \mathrm{kg}$ bw/d no linear dose response relationship was apparent in any organ tested, although the doses were escalated by a constant factor of 10 .

Of note, earlier results from the administration of higher single oral doses of AA to rodents have shown a relatively even distribution of DNA adducts in a spectrum of organs. $N^{7}$-GA-Gua adduct concentrations found in liver DNA of AA treated mice have been shown to be comparable to those determined in tumor target tissues. Altogether, this does not support the premise that induction of DNA damage is relevant for the neoplastic effects of AA in target organs of experimental animals (Doerge et al. 2005; Gamboa da Costa et al. 2003; Ghanayem et al. 2005; Manière et al. 2005).

Remarkably, MA excretion in urine of untreated controls indicated some background AA exposure of presumed endogenous origin in SD rats. This was concluded from the quantitative comparison of AA intake in food with the urinary mercapturic acid output. Control rats were estimated to ingest with their experimental diet at best $0.4 \mathrm{nmol} / \mathrm{day}$ $(0.1 \mu \mathrm{g} / \mathrm{kg} \mathrm{bw})$. This estimate was based on a maximum daily uptake of $30-50 \mathrm{~g}$ of the experimental diet with an AA content of $0.5 \mu \mathrm{g} / \mathrm{kg}$ (in fact it was below because $0.5 \mu \mathrm{g} /$ $\mathrm{kg}$ was the limit of detection). The total MA urinary output reached about $0.8 \mathrm{nmol} /$ day, estimated about equivalent to $0.6-0.7 \mu \mathrm{g} / \mathrm{kg}$ bw of AA exposure, thus substantially exceeding the maximum supposed AA intake (Watzek et al. 2012a).
The endogenous background found in SD rats is of similar magnitude as has been reported subsequently for humans where sustained endogenous background exposure was discovered and was estimated to be relatively close to the average dietary consumers' exposure (Goempel et al. 2017; Goerke et al. 2019; Ruenz et al. 2016; Watzek et al. 2012b).

It appears meaningful at this point to put the abovereported DNA adduct yields (1-2 adducts in 100 million nucleotides) into perspective, by reference to the human background levels reported for various tissues or cells. DNA adduct levels reflecting background exposure to genotoxic agents of various origin have been found in human tissues at levels of up to about 200 adducts in 100 million $\left(10^{8}\right)$ nucleotides (Nakamura et al. 2014; Swenberg et al. 2011). Considering adducts structurally more closely related to $N^{7}$-GAGua, such as $N^{7}$-2-carboxyethyl-Gua, $N^{7}$-2-hydroxyethyl- or $N^{7}$-methyl-Gua, aggregated background levels may together make up for a range of about $50-100 / 10^{8}$ nucleotides (summarized in Watzek et al. 2012a; Hartwig et al. 2020).

It thus may be inferred that up to the dose of $100 \mu \mathrm{g} / \mathrm{kg}$ bw which substantially (by a factor at least 100) exceeded human average dietary exposure levels, there was no indication for a dose-related induction of DNA damage in rats. GA specific DNA adduct levels remained at the lower bound of closely related human background DNA adducts.

\section{Evidence from toxicogenomic and transcriptional profiling data}

Several toxicogenomic studies in rodents exposed up to relatively high doses of AA were conducted and gene expression profiling was performed to approach elucidation of key MOA(s) (Chepelev et al. 2017, 2018; Recio et al. 2017). They are of interest because they address potential MOAs in the main rodent target tissues of AA-induced neoplastic changes, the thyroid, the testes, and the Harderian gland.

Taken together, the results of these transcriptional profiling studies did not show alterations of gene expression profiles indicative for pathways associated with putative genotoxic MOAs such as those involving p53 homeostasis, DNA repair, or the cell cycle orchestrating network. Instead, the findings pointed to alternative MOA(s). In animals exposed to dosages of $1.5-24.0 \mathrm{mg} / \mathrm{kg}$ bw AA in drinking water for up to 31 days, pronounced effects on genes involved in calcium signalling and cellular transport were observed, concomitant with cytoskeletal processes in target tissues. However, no evidence supporting a genotoxic MOA became apparent, even at the rather high dosages applied (Chepelev et al. 2017, 2018; Recio et al. 2017).

Overall, therefore, perturbation of calcium signalling pathways was discovered as a potential key event for AAmediated neoplastic transformation in these rodent tissues. The biomolecular details of how AA interferes with cellular 
calcium signalling and homeostasis to finally bring about neoplastic transformation are not clear yet.

In support of the premise that genotoxicity is not a probable MOA of AA, a further study in F 344 rats given AA at dosages up to $12.0 \mathrm{mg} / \mathrm{kg}$ bw/day for various subchronic time periods has shown no significant increase in either mutation of the Pig-a (phosphatidylinositol glycan, class A) gene, nor induction of micronuclei. Whereas at exceedingly high dosage levels of up to $24.0 \mathrm{mg} / \mathrm{kg}$ bw/day in mice some increase in micronuclei was observed, no Pig-a gene mutations were recorded (Hobbs et al. 2016). In addition, at dosages $<6.0 \mathrm{mg} / \mathrm{kg} / \mathrm{day}$ no in vivo mutagenicity was observed, in agreement with the perception of a nongenotoxic MOA for AA-induced tumorigenicity in rodents (Hobbs et al. 2016).

Taken together, these results are in line with those mentioned above and not supportive for a key role of genotoxicity in the mode of action of AA.

\section{Conclusions}

The totality of present-day evidence does not support the premise that AA induces malignant transformation in animal experiments by virtue of a genotoxic MOA. Whereas AA itself undoubtedly is nongenotoxic, it can be converted metabolically to the epoxide GA which may exert DNA damage by covalent binding. It has been presumed that such genetic damage may result in fixed mutations, eventually leading to neoplastic transformation. Although this view has been favoured in the past as the most probable key event underlying AA-induced neoplastic transformation, compelling evidence is lacking. As summarized here, the genotoxicity of AA may rather be understood as an effect occurring, if at all, at exceedingly high dose levels, not relevant to realistic physiological conditions, especially not to those prevailing at consumers' dietary exposure level. Thus, whereas genotoxicity does not appear to be a key MOA relevant for neoplastic transformation by AA, there is scientific evidence for a nongenotoxic MOA to be responsible for tumor formation in rodents. Tumors found enhanced in rodents are, however, considered to be strain and species-specific, not likely predictive for humans.

Taken together, this may argue for the establishment of an alternative, MOA based point of departure (POD) for risk assessment and/or the definition of a tolerable daily intake level (TDI) on the basis of a compellingly established no observed adverse effect (NOAEL) level.

Summarizing the major arguments, it is concluded that

- The presumed genotoxic key metabolite of AA, GA is a rather poor mutagen, predominantly inducing $N^{7}$-GA-
Gua lesions, known to be of rather low (or even absent) mutagenic activity at biologically relevant doses.

- In-vivo, at realistic low exposure levels encompassing diet-related intake, AA induces only very minor DNA damage in rats. At single dosages up to at least $100 \mu \mathrm{g} / \mathrm{kg}$ bw (which strongly exceeds present-day average consumer exposure), DNA damage was not found dose-related and remained at the lower bound of human background DNA damage of comparable DNA $N^{7}$-Gua lesions.

- Repeated intake of AA in foods/water at dosages of $50-100 \mu \mathrm{g} / \mathrm{kg}$ bw resulted in linear time- and exposurerelated cumulative buildup of $\mathrm{AA} \mathrm{Hb}$ adducts in blood erythrocytes. However, Hb-GA adducts were not found enhanced, although the mercapturic acid GAMA indicated significant GA formation in the liver. This allows us to conclude that up to the AA dose levels ingested, any GA formed metabolically in the liver will be scavenged by glutathione coupling. This conclusion is further supported by in vitro data in primary hepatocytes demonstrating the detoxifying formation of GSH adducts to be up to about 3 times faster than GA formation.

- Recent evidence from toxicogenomic studies argues for MOAs other than genotoxicity. This applies especially to the target organs of AA in rodent carcinogenicity studies, such as thyroid, testes, and Harderian gland, where pronounced effects on calcium signalling and on cytoskeletal functions have been observed, however, no compelling evidence was found to support a genotoxic MOA.

- Longterm studies on neoplastic effects of AA have revealed the enhanced formation of mammary gland adenomas and fibroadenomas, thyroid follicular cell neoplasms, and testicular mesotheliomas in F344 rats and in mice tumors in the Harderian gland, mammary gland, lung, ovary, skin, and stomach/forestomach. At variance, in another rat strain (Wistar Han rats) tumor responses were largely limited to the thyroid and mammary glands. These rodent neoplasms may be considered as speciesand strain-specific responses with specific modes of action not likely predictive for human cancer risk.

As an overall conclusion, the totality of presently available scientific evidence clearly argues against a genotoxic MOA underlying the neoplastic effects of AA, considered more likely to arise as sequelae of toxic effects, as exemplified by interference with the cellular calcium signalling system in target tissues.

Acknowledgements Open Access funding provided by Projekt DEAL. 


\section{Compliance with ethical standards}

Conflict of interest The author declares that he has no conflict of interest.

Open Access This article is licensed under a Creative Commons Attribution 4.0 International License, which permits use, sharing, adaptation, distribution and reproduction in any medium or format, as long as you give appropriate credit to the original author(s) and the source, provide a link to the Creative Commons licence, and indicate if changes were made. The images or other third party material in this article are included in the article's Creative Commons licence, unless indicated otherwise in a credit line to the material. If material is not included in the article's Creative Commons licence and your intended use is not permitted by statutory regulation or exceeds the permitted use, you will need to obtain permission directly from the copyright holder. To view a copy of this licence, visit http://creativecommons.org/licenses/by/4.0/.

\section{References}

Alison RH, Capen CC, Prentice DE (1994) Neoplastic lesions of questionable significance to humans. Toxicol Pathol 22:179-186. https ://doi.org/10.1177/019262339402200211

Bartsch R, Brikmann B, Jahnke G, Laube B, Lohmann R, Michaelsen S, Neumann I, Greim H (2018) Human relevance of follicular thyroid tumors in rodents caused by non-genotoxic substances. Regul Toxicol Pharmacol 98:199-208. https://doi.org/10.1016/j. yrtph.2018.07.025

Baum M, Fauth E, Fritzen S, Herrmann A, Mertes P, Rudolphi M, Spormann T, Zankl H, Eisenbrand G, Bertow D (2005a) Acrylamide and glycidamide: approach towards risk assessment based on biomarker guided dosimetry of genotoxic/mutagenic effects in human blood. Adv Exp Med Biol 561:77-88. https://doi. org/10.1007/0-387-24980-X_6

Baum M, Fauth E, Fritzen S, Herrmann A, Mertes P, Merz KH, Rudolphi M, Zankl H, Eisenbrand G (2005b) Acrylamide and glycidamide: genotoxic effects in V79-cells and human blood. Mutat Res 580:61-69. https://doi.org/10.1016/j.mrgentox.2004.11.007

Baum M, Loeppky RN, Thielen S, Eisenbrand G (2008) Genotoxicity of glycidamide in comparison to 3-N-nitroso-oxazolidin-2-one. J Agric Food Chem 56(15):5989-5993. https://doi.org/10.1021/ jf703741a

Beland FA, Mellick PW, Olson GR, Mendoza MC, Marques MM, Doerge DR (2013) Carcinogenicity of acrylamide in B6C3F(1) mice and $\mathrm{F} 344 / \mathrm{N}$ rats from a 2-year drinking water exposure. Food Chem Toxicol 51:149-159. https://doi.org/10.1016/j. fct.2012.09.017

Ben-Jonathan N, LaPensee CR, LaPensee EW (2008) What can we learn from rodents about prolactin in humans. Endocr Rev 29:141. https://doi.org/10.1210/er.2007-0017

Berger FI, Feld J, Bertow D, Eisenbrand G, Fircker G, Gerhardt N, Merz K-H, Richling E, Baum M (2011) Biological effects of acrylamide after daily ingestion of various foods in comparison to water: a study in rats. Mol Nutr Food Res 55(3):387-399. https ://doi.org/10.1002/mnfr.201000234

Bertow D, (2009) Molekulare Toxikologie von Acrylamid anhand der Analytik von Proteinaddukten. Vom Fachbereich Chemie der Technischen Universität Kaiserslautern zur Verleihung des akademischen Grades „Doktor der Naturwissenschaften“"genehmigte Dissertation
Boysen G, Pachkowski BF, Nakamura J, Swenberg JA (2009) The formation and biological significance of N7-guanine adducts. Mutat Res 678(2):76-94. https://doi.org/10.1016/j.mrgen tox.2009.05.006

Calleman CJ, Bergmark E, Costa LG (1990) Acrylamide is metabolized to glycidamide in the rat: evidence from hemoglobin adduct formation. Chem Res Toxicol 3(5):406-412. https://doi.org/10.1021/ tx00017a004

Capen CC (1997) Mechanistic data and risk assessment of selected toxic end points of the thyroid gland. Toxicol Pathol 25(1):39-48. https://doi.org/10.1177/019262339702500109

Capen CC, Martin SL (1989) The effects of xenobiotics on the structure and function of thyroid follicular and C-cells. Toxicol Pathol 17(2):266-293. https://doi.org/10.1177/019262338901700205

Chepelev NL, Gagné R, Maynor T, Kuo B, Hobbs CA, Recio L, Yauk CL (2017) Transcriptional profiling of male F344 rats suggests the involvement of calcium signaling in the mode of action of acrylamide-induced thyroid cancer. Food Chem Toxicol 107(Part A):186-200. https://doi.org/10.1016/j.fct.2017.06.019

Chepelev NL, Gagné R, Maynor T, Kuo B, Hobbs CA, Recio L, Yauk CL (2018) Transcriptional profiling of male CD-1 mouse lungs and Harderian glands supports the involvement of calcium signaling in acrylamide-induced tumors. Regul Toxicol Pharmacol 95:75-90. https://doi.org/10.1016/j.yrtph.2018.02.005

Collins JJ, Swaen GM, Marsh GM, Utidjian HM, Caporossi JC, Lucas LJ (1989) Mortality patterns among workers exposed to acrylamide. J Occup Med 31(7):614-617. https://doi.org/10.1097/00043 764-198907000-00013

Doerge DR, Gamboa da Costa G, McDaniel LP, Churchwell MI, Twaddle NC, Beland FA (2005) DNA adducts derived from administration of acrylamide and glycidamide to mice and rats. Mutat Res 580(1-2):131-141. https://doi.org/10.1016/j.mrgen tox.2004.10.013

Dourson M, Hertzberg R, Allen B, Haber L, Parker A, Kroner O, Maier A, Kohrman M (2008) Evidence-based dose-response assessment for thyroid tumorigenesis from acrylamide. Regul Toxicol Pharmacol 52(3):264-289. https://doi.org/10.1016/j.yrtph.2008.08.004

EFSA (European Food Safety Agency) (2005) Opinion of the scientific committee on a request from EFSA related to a harmonized approach for risk assessment of substances which are both genotoxic and carcinogenic. EFSA J 282:1-31. https://doi. org/10.2903/j.efsa.2005.282

EFSA (2011) Scientific opinion on genotoxicity testing strategies applicable to food and feed safety assessment. EFSA J 9(9):2379. https ://doi.org/10.2903/j.efsa.2011.2379

EFSA (2015) Scientific Opinion on acrylamide in food. EFSA J 13(6):4104. https://doi.org/10.2903/j.efsa.2015.4104

EU (European Union) (2017) COMMISSION REGULATION (EU) 2017/2158, Establishing mitigation measures and benchmark levels for the reduction of the presence of acrylamide in food (Text with EEA relevance) http://data.europa.eu/eli/reg/2017/2158/oj

Fennell TR, Friedman MA (2005) Comparison of acrylamide metabolism in humans and rodents. Adv Exp Med Biol 561:109-116. https://doi.org/10.1007/0-387-24980-X_9

Food Drink Europe (2019) Acrylamide Toolbox https://www.foodd rinkeurope.eu/uploads/publications_documents/FoodDrinkEurope _Acrylamide_Toolbox_2019.pdf

Friedman MA, Dulak LH, Stedham MA (1995) A lifetime oncogenicity study in rats with acrylamide. Fundam Appl Toxicol 27(1):95105. https://doi.org/10.1006/faat.1995.1112

Fuhr U, Boettcher MI, Kinzig-Schippers M, Weyer A, Jetter A, Lazar A, Taubert D, Tomalik-Scharte D, Pournara P, Jakob V, Harlfinger S, Klaassen T, Berkessel A, Angerer J, Sörgel F, Schömig E (2006) Toxicokinetics of acrylamide in humans after ingestion of a defined dose in a test meal to improve risk assessment for 
acrylamide carcinogenicity. Cancer Epidemiol Biomark Prev 15:266-271. https://doi.org/10.1158/1055-9965.EPI-05-0647

Gamboa da Costa G, Churchwell MI, Hamilton LP, Von Tungeln LS, Beland FA, Marques MM, Doerge DR (2003) DNA adduct formation from acrylamide via conversion to glycidamide in adult and neonatal mice. Chem Res Toxicol 16(10):1328-1337. https://doi. org/10.1021/tx034108e

Ghanayem BI, McDaniel LP, Churchwell MI, Twaddle NC, Snyder R, Fennell TR, Doerge DR (2005) Role of CYP2E1 in the epoxidation of acrylamide to glycidamide and formation of DNA and hemoglobin adducts. Toxicol Sci 88(2):311-318. https://doi. org/10.1093/toxsci/kfi307

Goempel K, Tedsen L, Ruenz M, Bakuradze T, Schipp D, Galan J, Eisenbrand G, Richling E (2017) Biomarker monitoring of controlled dietary acrylamide exposure indicates consistent human endogenous background. Arch Toxicol 91(11):3551-3560. https ://doi.org/10.1007/s00204-017-1990-1

Goerke K, Ruenz M, Lampen A, Abraham K, Bakuradze T, Eisenbrand G, Richling E (2019) Biomonitoring of nutritional acrylamide intake by consumers without dietary preferences as compared to vegans. Arch Toxicol 93(4):987-996. https://doi.org/10.1007/ s00204-019-02412-x

Gooderham NJ, Cohen SS, Eisenbrand G, Fukushima S, Guengerich FP, Hecht SS, Rietjens IMCM, Rosol T, Bastaki M, Linman MJ, Taylor SV (2020) The safety evaluation of food flavoring substances: the role of genotoxicity studies. Crit Rev Toxicol. https ://doi.org/10.1080/10408444.2020.1712589

Hartwig A, Arand M, Epe B, Guth S, Jahnke G, Lampen A, Martus HJ, Monien B, Rietjens IMCM, Schmitz-Spanke S, SchrieverSchwemmer G, Steinberg P, Eisenbrand G (2020) Considerations on the establishment of limit values for the risk assessment of genotoxic carcinogens. Arch Toxicol (submitted)

Hashimoto K, Tanii H (1985) Mutagenicity of acrylamide and its analogues in Salmonella typhimurium. Mutat Res 158(3):129133. https://doi.org/10.1016/0165-1218(85)90075-8

Hobbs CA, Davis J, Shepard K, Chepelev N, Friedman M, Marroni D, Recio L (2016) Differential genotoxicity of acrylamide in the micronucleus and Pig-a gene mutation assays in F344 rats and B6C3F1 mice. Mutagenesis 31(6):617-626. https://doi. org/10.1093/mutage/gew028

Jiang L, Cao J, An Y, Geng C, Qu S, Jiang L, Zhong L (2007) Genotoxicity of acrylamide in human hepatoma G2 (HepG2) cells. Toxicol In Vitro 21(8):1486-1492. https://doi.org/10.1016/j. tiv.2007.06.011

Johnson KA, Gorzinski SJ, Bodner KM, Campbell RA, Wolf CH, Friedman MA, Mast RW (1986) Chronic toxicity and oncogenicity study on acrylamide incorporated in the drinking water of Fischer 344 rats. Toxicol Appl Pharmacol 85(2):154-168. https://doi.org/10.1016/0041-008x(86)90109-2

Khan MA, Davis CA, Foley GL, Friedman MA, Hansen LG (1999) Changes in thyroid gland morphology after acute acrylamide exposure. Toxicol Sci 47(2):151-157. https://doi.org/10.1093/ toxsci/47.2.151

Kiwamoto R, Spenkelink A, Rietjens IM, Punt A (2015) An integrated QSAR-PBK/D modelling approach for predicting detoxification and DNA adduct formation of 18 acyclic food-borne $\alpha$, $\beta$-unsaturated aldehydes. Toxicol Appl Pharmacol 282(1):108117. https://doi.org/10.1016/j.taap.2014.10.014

Koyama N, Sakamoto H, Sakuraba M, Koizumi T, Takashima Y, Hayashi M, Matsufuji H, Yamagata K, Masuda S, Kinae N, Honma M (2006) Genotoxicity of acrylamide and glycidamide in human lymphoblastoid TK6 cells. Mutat Res 603(2):151158. https://doi.org/10.1016/j.mrgentox.2005.11.006

Lamy E, Völkel Y, Roos PH, Kassie F, Mersch-Sundermann V (2008) Ethanol enhanced the genotoxicity of acrylamide in human, metabolically competent HepG2 cells by CYP2E1 induction and glutathione depletion. Int J Hyg Environ Health 211(1-2):74-81. https://doi.org/10.1016/j.ijheh.2007.04.004

Manière I, Godard T, Doerge DR, Churchwell MI, Guffroy M, Laurentie M, Poul JM (2005) DNA damage and DNA adduct formation in rat tissues following oral administration of acrylamide. Mutat Res 580(1-2):119-129. https://doi.org/10.1016/j.mrgen tox.2004.10.012

Maronpot RR, Zeiger E, McConnell EE, Kolenda-Roberts H, Wall H, Friedman MA (2009) Induction of tunica vaginalis mesotheliomas in rats by xenobiotics. Crit Rev Toxicol 39(6):512-537. https://doi.org/10.1080/10408440902969430

Maronpot RR, Thoolen RJ, Hansen B (2015) Two-year carcinogenicity study of acrylamide in Wistar Han rats with in utero exposure. Exp Toxicol Pathol 67(2):189-195. https://doi. org/10.1016/j.etp.2014.11.009

Maronpot RR, Nyska A, Foreman J, Ramot Y (2016) The legacy of the F344 rat as a cancer bioassay model (a retrospective summary of three common F344 rat neoplasms). Crit Rev Toxicol 46(8):641-675. https://doi.org/10.1080/10408444.2016.11746 69

Marsh GM, Lucas LJ, Youk AO, Schall LC (1999) Mortality patterns among workers exposed to acrylamide: 1994 follow up. Occup Environ Med 56(3):181-190. https://doi.org/10.1136/ oem.56.3.181

Marsh GM, Youk AO, Buchanich JM, Kant IJ, Swaen G (2007) Mortality patterns among workers exposed to acrylamide: updated follow up. J Occup Environ Med 49(1):82-95. https://doi.org/10.1097/ JOM.0b013e31802db536

Mei N, Hu J, Churchwell MI, Guo L, Moore MM, Doerge DR, Chen T (2008) Genotoxic effects of acrylamide and glycidamide in mouse lymphoma cells. Food Chem Toxicol 46(2):628-636. https://doi. org/10.1016/j.fct.2007.09.093

Nakamura J, Mutlu E, Sharma V, Collins L, Bodnar W, Yu R, Lai Y, Moeller B, Lu K, Swenberg J (2014) The endogenous exposome. DNA Repair 19:3-13. https://doi.org/10.1016/j.dnare p.2014.03.031

Nestmann ER, Bryant DW, Carr CJ (1996) Toxicological significance of DNA adducts: summary of discussions with an expert panel. Regul Toxicol Pharmacol 24(1 Pt 1):9-18. https://doi. org/10.1006/rtph.1996.0059

Neumann F (1991) Early indicators for carcinogenesis in sex-hormone sensitive organs. Mutat Res 248:341-356. https://doi. org/10.1016/0027-5107(91)90067-X

Pelucchi C, La Vecchia C, Bosetti C, Boyle P, Boffetta P (2011) Exposure to acrylamide and human cancer-a review and meta-analysis of epidemiologic studies. Ann Oncol 22(7):1487-1499. https:// doi.org/10.1093/annonc/mdq610

Poteracki J (1998) Walsh CM (1989) Spontaneous neoplasms in control wistar rats: a comparison of reviews. Toxicol Sci 45:1-8

Puppel N, Tjaden Z, Fueller F, Marko D (2005) DNA strand breaking capacity of acrylamide and glycidamide in mammalian cells. Mutat Res 580(1-2):71-80. https://doi.org/10.1016/j.mrgen tox.2004.11.009

Recio L, Friedman M, Marroni D, Maynor T, Chepelev NL (2017) Impact of acrylamide on calcium signaling and cytoskeletal filaments in testes from F344 Rat. Int J Toxicol 36(2):124-132. https ://doi.org/10.1177/1091581817697696

Ruenz M, Bakuradze T, Eisenbrand G, Richling E (2016) Monitoring urinary mercapturic acids as biomarkers of human dietary exposure to acrylamide in combination with acrylamide uptake assessment based on duplicate diets. Arch Toxicol 90(4):873-881. https://doi.org/10.1007/s00204-015-1494-9

Ruenz M, Goerke K, Bakuradze T, Abraham K, Lampen A, Eisenbrand G, Richling E (2019) Sustained Human Background Exposure to Acrolein Evidenced by Monitoring Urinary Exposure Biomarkers. 
Mol Nutr Food Res 63(24):e1900849. https://doi.org/10.1002/ mnfr.201900849

Segerbäck D, Calleman CJ, Schroeder JL, Costa LG, Faustman EM (1995) Formation of N-7-(2-carbamoyl-2-hydroxyethyl)guanine in DNA of the mouse and the rat following intraperitoneal administration of [14C] acrylamide. Carcinogenesis 16(5):1161-1165. https://doi.org/10.1093/carcin/16.5.1161

Settels E, Bernauer U, Palavinskas R, Klaffke HS, Gundert-Remy U, Appel KE (2008) Human CYP2E1 mediates the formation of glycidamide from acrylamide. Arch Toxicol 82(10):717-727. https:// doi.org/10.1007/s00204-008-0296-8

Shipp A, Lawrence G, Gentry R, McDonald T, Bartow H, Bounds J, Macdonald N, Clewell H, Allen B, Van Landingham C (2006) Acrylamide: review of toxicity data and dose-response analyses for cancer and noncancer effects. Crit Rev Toxicol 36(6-7):481608. https://doi.org/10.1080/10408440600851377

Sobel W, Bond GG, Parsons TW, Brenner FE (1986) Acrylamide cohort mortality study. Br J Ind Med 43(11):785-788. https:// doi.org/10.1136/oem.43.11.785

Sumner SC, Fennell TR, Moore TA, Chanas B, Gonzalez F, Ghanayem BI (1999) Role of cytochrome P450 2E1 in the metabolism of acrylamide and acrylonitrile in mice. Chem Res Toxicol 12(11):1110-1116. https://doi.org/10.1021/tx990040k

Swaen GMH, Haidar S, Burns CJ, Bodner K, Parsons T, Collins JJ, Baase C (2007) Mortality study update of acrylamide workers. Occup Environ Med 64(6):396-401. https://doi.org/10.1136/ oem.2006.030130

Swenberg JA, Lu K, Moeller BC, Gao L, Upton PB, Nakamura J, Starr TB (2011) Endogenous versus exogenous DNA adducts: their role in carcinogenesis, epidemiology, and risk assessment. Toxicol Sci 120(Suppl 1):S130-145. https://doi.org/10.1093/toxsci/kfq371

Tareke E, Rydberg P, Karlsson P, Eriksson S, Tärnqvist M (2002) Analysis of acrylamide, a carcinogen formed in heated foodstuffs. J Agric Food Chem 50(17):4998-5006. https://doi.org/10.1021/ jf020302f
Thielen S, Baum M, Hoffmann M, Loeppky RN, Eisenbrand G (2006) Genotoxicity of glycidamide in comparison to $( \pm)$-anti-benzo[a] pyrene-7,8-dihydrodiol-9,10-epoxide and alpha-acetoxy-Nnitroso-diethanolamine in human blood and in mammalian V79-cells. Mol Nutr Food Res 50(4-5):430-436. https://doi. org/10.1002/mnfr.200500227

Watzek N, Böhm N, Feld J, Scherbl D, Berger F, Merz KH, Lampen A, Reemtsma T, Tannenbaum SR, Skipper PL, Baum M, Richling E, Eisenbrand G (2012a) N7-glycidamide-guanine DNA adduct formation by orally ingested acrylamide in rats: a dose-response study encompassing human diet-related exposure levels. Chem Res Toxicol 25(2):381-390. https://doi.org/10.1021/tx200446z

Watzek N, Scherbl D, Feld J, Berger F, Doroshyenko O, Fuhr U, Tomalik-Scharte D, Baum M, Eisenbrand G, Richling E (2012b) Profiling of mercapturic acids of acrolein and acrylamide in human urine after consumption of potato crisps. Mol Nutr Food Res 56(12):1825-1837. https://doi.org/10.1002/mnfr.201200323

Watzek N, Scherbl D, Schug M, Hengstler JG, Baum M, Habermeyer M, Richling E, Eisenbrand G (2013) Toxicokinetics of acrylamide in primary rat hepatocytes: coupling to glutathione is faster than conversion to glycidamide. Arch Toxicol 87(8):1545-1556. https ://doi.org/10.1007/s00204-013-1054-0

Zhivagui M, Alvin WTNG, Ardin M, Churchwell MI, Pandey M, Renard C, Villar S, RobitailleA Bouaoun L, Heguy A, Guyton KZ, Stampfer MR, McKay J, Hollstein M, Olivier M, Rozen SG, Beland FA, Korenjak M, Zavadil J (2019) Experimental and pan-cancer genome analysis reveal widespread contribution of acrylamide exposure to carcinogenesis in humans. Genome Res. 29:1-11

Publisher's Note Springer Nature remains neutral with regard to jurisdictional claims in published maps and institutional affiliations. 